\title{
Statement on mouth cancer diagnosis and prevention
}

\author{
IN BRIEF \\ - What is mouth cancer? \\ What can you do to reduce the risk and \\ spot mouth cancer early? \\ - What can be done to reduce the burden \\ of mouth cancer?
}

\author{
C. Scully*1 and J. Kirby ${ }^{2}$
}

The number of people being diagnosed with mouth cancer (oral cancer) is increasing, with notable rises in incidence in younger people and in females. There are certain lifestyle habits that can increase the risk of mouth cancer, such as smoking or chewing tobacco, drinking alcohol above recommended levels (especially in those who also smoke), and chewing betel nut (areca nut). Infection with human papillomavirus (HPV) increases the risk of some types of mouth cancer, and too much sun exposure may also raise the risk of lip cancers. The signs and symptoms of mouth cancer can often be seen or felt, and any red or white patch, ulcer or lump can be an early sign if it lasts for three or more weeks. If people notice any of these changes, they should seek help from their dentist, doctor, or another healthcare professional without delay, because if mouth cancer is diagnosed at an early stage, when the lesions are small, treatment is generally less complicated and more effective.

\section{WHAT IS MOUTH CANCER?}

Mouth cancer is the largest group of head and neck cancers. It is more common in men than in women, and the vast majority of cases are in people over the age of 50 . However, more than one in ten cases is diagnosed in people below this age. Incidence rates in Scotland are the highest of all the UK nations. Mouth cancer rates are also high among South Asian women.

There appear to be two distinct pathways to cancer in the mouth - most lesions (around 75\%) are related to use of tobacco or alcohol, but some, especially at the back of the mouth in the oropharynx, are related to exposure to human papillomavirus (HPV).

Mouth cancer is changing. It is increasing in younger patients (there has been a significant increase in patients under the age of 45 over the last 20 years). Although rates of

\footnotetext{
${ }^{1 * B r i t i s h}$ Society for Oral Medicine (BSOM), ${ }^{2}$ Cancer Research UK (CRUK)

Joint statement with the Chief Dental Officers of England, Wales, Northern Ireland and Scotland; the Royal Colleges Dental Faculty Deans in England, Edinburgh and Glasgow; the British Dental Association (BDA); the British Dental Health Foundation (BDHF); the British Society for Oral and Maxillofacial Pathology (BSOMP), the British Association of Oral \& Maxillofacial Surgeons (BAOMS), the British Association of Oral Surgeons

(BAOS), and the Association of British Academic Oral \& Maxillofacial Surgeons (ABAOMS)

* Correspondence to: Professor Crispian Scully

Email: crispian.scully@ucl.ac.uk
}

\section{Refereed Paper}

Accepted 11 November 2013

DOI: $10.1038 /$ sj.bdj.2013.1235

${ }^{\circ}$ British Dental Journal 2014; 216: 37-38 mouth cancer have traditionally been higher in men than in women, this gap is narrowing over time.

There is an urgent need for action against mouth cancer. Although patients' quality of life during and after treatment has steadily improved, survival rates from the disease have barely increased. ${ }^{2}$

The stage at which mouth cancer is diagnosed has a significant effect on overall survival. When the cancer is still confined to the primary site and small (stage I, less than $2 \mathrm{~cm}$ ), nearly 90\% of people survive for at least two years. But six out of ten mouth cancers are found at a late stage (stages III and IV, greater than $4 \mathrm{~cm}$ or with spread), and this means a much lower survival rate (at stage IV, around 45\% of people survive for at least two years) and high treatmentrelated morbidity in those who survive.

Delays in diagnosis of oral cancer can lead to patients having more advanced stages of cancer, especially when the delay is more than a month. Delays in referral from primary to secondary care are associated with a threefold increase in mortality.

\section{WHAT CAN YOU DO TO REDUCE THE RISK AND SPOT MOUTH CANCER EARLY?}

There are a number of things you can do to reduce the risk of developing mouth cancer. These include:

- Avoid using tobacco in any form smoked, chewed, or smokeless

- Avoid using betel nut (or areca nut), even without tobacco

- Cut down on alcohol: aim to drink no more than one standard drink a day (2-3 units) for women, or two standard drinks a day (3-4 units) for men

- Eat at least five servings of fruit and vegetables a day

- Protect your lips with sunscreen and a wide-brimmed hat, and spend time in the shade when the sun's UV rays are strong

- Reduce chances of infection with HPV by practising safer sex.

By living such a healthy lifestyle, you can cut down the risk of mouth cancer, and also gain a wide range of other health benefits.

To spot mouth cancer early, get to know what is normal for you, and if you notice anything out of the ordinary in your mouth, tell your dentist, doctor or another healthcare professional without delay.

Particular signs to look out for are any red or white patch, ulcer, or lump in the mouth, which can be an early sign of cancer if lasting for three or more weeks.

Also, have yearly examinations by a dentist, even if you no longer have your own teeth. Dentists are trained to spot early signs of mouth cancer and can easily see parts of your mouth that you cannot see.

\section{WHAT CAN BE DONE TO REDUCE} THE BURDEN OF MOUTH CANCER?

There is an urgent need to rapidly develop the following: 


\section{Better public awareness} and knowledge

- Continuing public awareness activity, such as that conducted during Mouth Cancer Action Month, is needed to raise understanding of mouth cancer, risk and prevention, and early diagnosis

- Mouth cancer awareness-raising activity could also be carried out through the Department of Health 'Be Clear on Cancer' umbrella.

\section{Better professional} awareness and knowledge

- It is important that high uptake of good quality continuing professional development (CPD) programmes is encouraged

- 'Oral Cancer: Early detection' is an important topic of the General Dental Council (GDC) guidance for CPD for dental professionals (www.gdc-uk. org/dentalprofessionals/cpd/Pages/default. aspx)

- The GDC should also consider making this a 'highly recommended' CPD subject.

\section{Better preventive strategies}

- Continued action on reducing tobacco use

- Renewed action on reducing alcohol consumption to within recommended levels

- Continued action to reduce areca nut (betel) use.

There is indicative evidence that HPV vaccination may be able to help prevent oral HPV infections. New and emerging evidence on HPV vaccination, including cost-effectiveness, can help inform whether to recommend HPV vaccination also for 12-13-year-old boys, or men who have sex with men. Further studies, using oral cancer incidence as endpoints, are also needed to provide firm evidence of a beneficial effect.

\section{Earlier diagnosis and referral for treatment}

- Research into how best to reduce referral and diagnostic delays, as well as implementation of strategies that are shown to be effective in reducing such delays.

The British Society for Oral Medicine (BSOM) and Cancer Research UK (CRUK); the Chief Dental Officers for England, Northern Ireland, Scotland, and Wales; the Deans of the British Royal Colleges of Surgeons Dental faculties; the British Dental Association (BDA); the British Dental Health Foundation (BDHF); the British Society for Oral and Maxillofacial Pathology (BSOMP); the British Association of Oral \& Maxillofacial Surgeons (BAOMS); the British Association of Oral Surgeons (BAOS); and the Association of British Academic Oral et Maxillofacial Surgeons (ABAOMS) support this statement and Mouth Cancer Action Month.

The National Clinical Director for Cancer, NHS England and the Platform for Better Oral Health in Europe also support the statement. 